\title{
Foreign bodies in otorhinolaryngology
}

\author{
Management and outcome
}

Ali S. Al-Qahtani, FACS, FISQua, Abdelaziz Qobty, MBBS, Abdullah Al-Shahrani, MBBS, Ali K. Alshehri, MBBS.

\section{ABSTRACT}

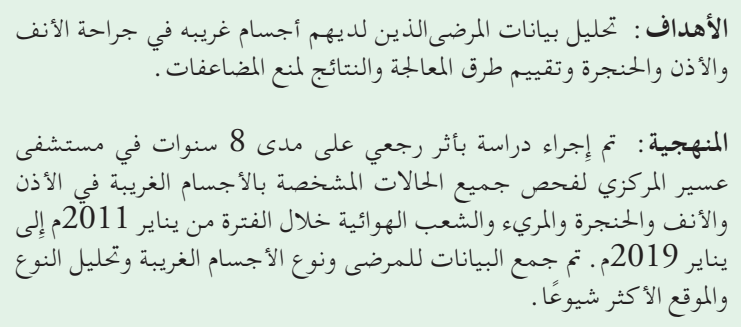

النتائج : تم قبول 184 مريضا بينهم 72 (60.1\%)

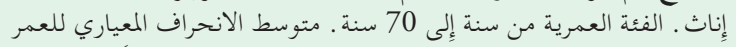

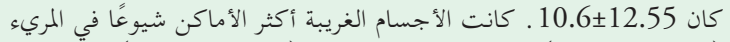

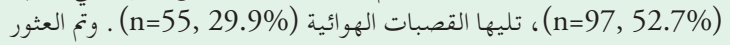
على فرق له دلال إِحصائية واضحة

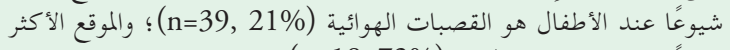

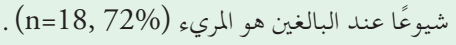

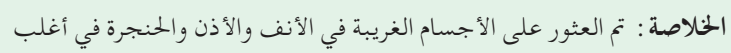

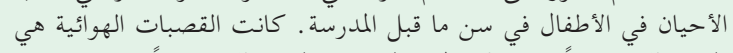

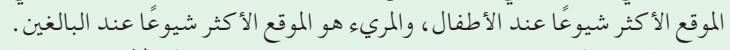

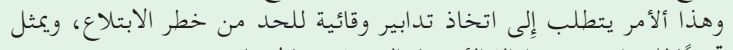

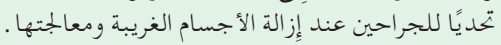

Objectives: To analyze the data of patients with otorhinolaryngological foreign bodies and to evaluate the management and outcomes of foreign bodies to prevent complications.

Methods: A retrospective study was conducted over 8 years at Aseer Central Hospital to examine all admitted cases with foreign bodies in the ear, nose, throat, esophagus and bronchus during the period from January 2011 to January 2019. Patient demographic data, type of foreign body, and most common site were analyzed.

Results: A total of 184 patients were admitted, including 72 (39.1\%) males and 112 (60.9\%) females. The age range was from one year old to 70 years old; the mean \pm standard deviation of age was $10.6 \pm 12.55$ years. Foreign bodies were most commonly located in the esophagus ( $\mathrm{n}=97,52.7 \%)$, followed by the bronchus $(\mathrm{n}=55,29.9 \%)$. A statistically significant difference was found, with a $p$-value of 0.00001 . The most common site in children was the bronchus $(\mathrm{n}=39,21 \%)$; the most common site in adults was the esophagus $(\mathrm{n}=18,72 \%)$.

Conclusion: Otorhinolaryngological foreign bodies are found most frequently in preschool-aged children. The most common site in children was the bronchus, and the most common site in adults was the esophagus. Prevention measures are essential to reduce the risk of ingestion and admission, which can be challenging.

Keywords: foreign bodies, esophagus, bronchus, outcome, management

Saudi Med J 2020; Vol. 41 (7): 715-719 doi: 10.15537/smj.2020.7.25137

From the Department of Otorhinolaryngology-Head and Neck Surgery (Al-Qahtani), College of Medicine (Alshehri), King Khalid University and from the Department of Otorbinolaryngology-Head \& Neck Surgery (Qobty, Al-Shahrani), Aseer Central Hospital, Abha, Kingdom of Saudi Arabia.

Received 8th May 2020. Accepted 23rd May 2020.

Address correspondence and reprint request to: Prof. Ali S. Al-Qabtani, Professor, Department of Otorhinolaryngology-Head and Neck Surgery, College of Medicine, King Khalid University, Abha, Kingdom of Saudi Arabia.E-mail:alqahtani@kku.edu.sa

ORCID ID: https://0000-0003-3409-5725

$\mathrm{O}$ torhinolaryngological foreign bodies are relatively common problems that are frequently encountered in emergency situations. ${ }^{1}$ Foreign bodies may affect any part of the head and neck, such as the nose, ears, throat, hypopharynx, bronchus and oesophagus. ${ }^{2-4}$ Common foreign bodies include food, plastics, beads, papers and toys. ${ }^{5,6}$ The presence and removal of foreign bodies, especially in the airway, can be challenging to operators and may lead to death.,8 
The aim of this study was to collect and review the data of patients with otorhinolaryngological foreign bodies with respect to the site of the foreign body, age of the patient, type of foreign body and method of removal and to evaluate the management and outcome of foreign bodies with the aim of minimizing the harmful consequences.

Methods. Approval from the Institutional Research and Ethics Committee was obtained from the College of Medicine, King Khalid University, Abha, Kingdom of Saudi Arabia. We reviewed the medical records of all patients who were admitted at Aseer Central Hospital with foreign bodies in the ear, nose, throat, esophagus or bronchus at our institute between January 2011 and January 2019. Patient age, gender, type of foreign body and most common site were analyzed. Patients were evaluated by complete history, physical examination and radiological investigation such as soft tissue neck lateral view and chest $\mathrm{x}$-ray.

Inclusion criteria for our patients of foreign body in ear, nose, throat, bronchus, trachea and esophagus over the last 8 years at Aseer Central Hospital. The exclusion criteria include patients less than one year of age or more than 70 years old and patient with hematological disorder.

All procedures were carried out under general anesthesia using rigid endoscopy for removal of foreign body for both esophagus and respiratory tract. Patients were followed immediately after the surgery to assess any complications and at the first week postoperatively. The management and outcome of procedure was assisted by group discussion of all authors.

Data analyses were performed by using Statistical Package for Social Sciences for Windows, version 22.0 (SPSS Inc., Chicago, IL, USA). Fisher's 95\% confidence intervals were calculated for the proportions. Pearson's Chi-square test was used as test of significance at the $5 \%$.

Results. There were 184 patients admitted to Aseer Central Hospital; most patients were admitted through the emergency department. The patients included 72 males (39.1\%) and 112 females (60.9\%). Their ages ranged from 1-70 years old with an average age of

Disclosure. Authors have no conflict of interests, and the work was not supported or funded by any drug company.
Table 1 - Distribution of the study sample by age and site of the foreign bodies.

\begin{tabular}{lccccc}
\hline Age & \multicolumn{5}{c}{ Site of the foreign body } \\
& Ear & Nose & Bronchus & Esophagus & Hypopharynx \\
\hline $\begin{array}{l}\text { Children } \\
(0-18)\end{array}$ & 16 & 6 & 39 & 18 & 7 \\
$\begin{array}{l}\text { Adults } \\
(19-70)\end{array}$ & 2 & 0 & 16 & 79 & 1 \\
\hline
\end{tabular}

$10.45 \pm 12.65$ years and a median age of 6 years. The most common site in children was the bronchus $(n=39$, $21 \%$ ), and the most common site in adults was the esophagus $(\mathrm{n}=18,72 \%)$ (Table 1$)$.

Regarding the distribution of the study sample by age group, preschool-aged children ( $1-5$ years old) were most prevalent $(\mathrm{n}=87,47.3 \%)$, followed by preadolescents aged $6-9$ years old $(n=40,21.7 \%)$ and adolescents aged $10-19$ years old $(\mathrm{n}=25,13.6 \%)$. There were 32 adults (>20 years old), accounting for $17.4 \%$ of the sample. The distribution of age groups did not significantly differ between genders $(p=0.431)$ (Figure 1). The most common site was the esophagus ( $\mathrm{n}=97,53 \%)$, followed by the bronchus $(n=55,30 \%)$. The highest prevalences of esophageal foreign bodies were observed among adolescents $(\mathrm{n}=18,72 \%)$ and adults $(\mathrm{n}=23,71 \%)$. The lowest prevalences of esophageal foreign bodies were observed among preschool children $(\mathrm{n}=29,33.3 \%)$ and preadolescents $(n=27,67.5 \%)$. The difference in the prevalences of esophageal foreign bodies between ages groups was statistically significant $(p=0.001)$. On the other hand, the highest prevalences of bronchial foreign bodies were observed among preschool-aged children $(n=39,44.8 \%)$ and preadolescents $(n=9,22.5 \%)$. The lowest prevalences of bronchial foreign bodies were observed among adolescents $(n=5,20 \%)$ and adults $(n=2,6.3 \%)$. The difference in the prevalences of bronchial foreign bodies between ages groups was statistically significant $(p=0.001)$ (Figure 2$)$. The most frequent procedure was esophagoscopy $(n=97)$, followed by bronchoscopy ( $n=55)$ (Figure 3 ). The most common foreign body was meat $(n=32)$, followed by coins $(n=28)$ and peanuts $(n=22)$. Other foreign bodies found in the study $(n=45)$ included teeth, toothpicks, buttons, wood, pearls, batteries, nails, pencils, rings, screws, seeds and earrings. Regarding the presence of meat as a foreign body, the highest prevalences were observed among adults $(\mathrm{n}=21,65.5 \%)$ and adolescents 


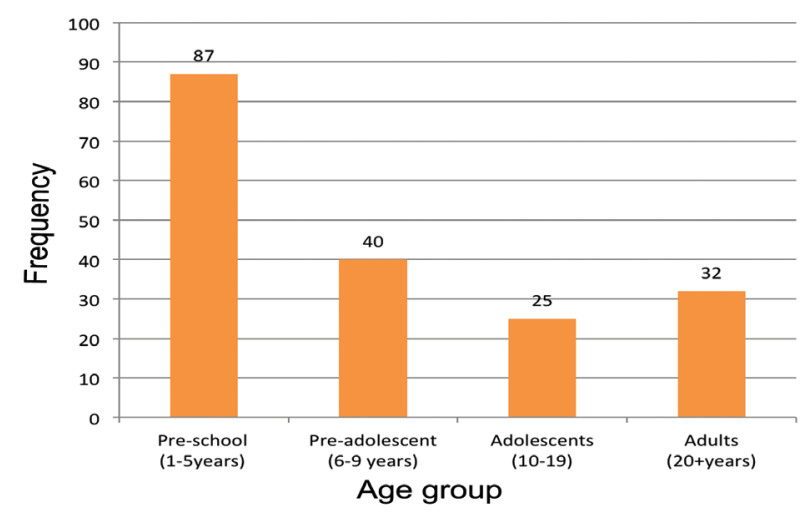

Figure 1 - Distribution of the study sample by age group.

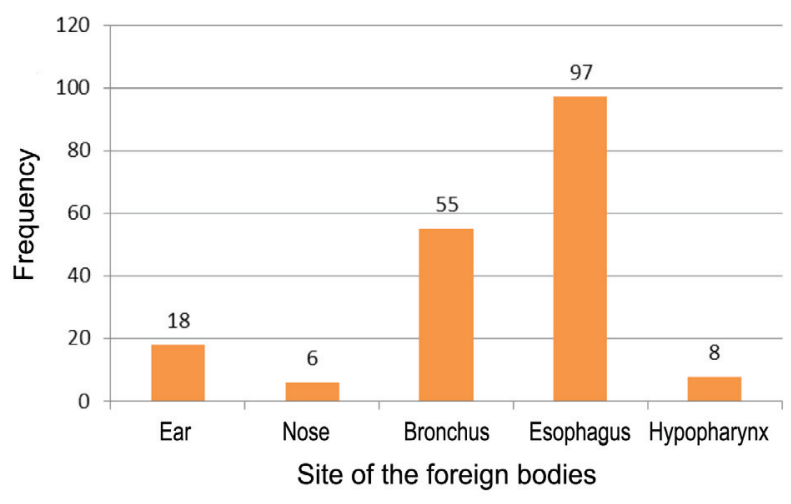

Figure 2 - Distribution of the study sample by site of the foreign bodies.

$(\mathrm{n}=5,12.5 \%)$. The lowest prevalence was observed among preschool-aged children $(\mathrm{n}=2,2.2 \%)$.

The difference in the prevalences of meat as a foreign body between ages groups was statistically significant $(p=0.001)$ (Figure 4).

Regarding the presence of coins as foreign bodies, the highest prevalences were observed among preadolescents $(n=13,32.5 \%)$ and adolescents $(n=5,20 \%)$. The lowest prevalence was observed among preschool-aged children $(\mathrm{n}=10,11.4 \%)$. No coins were found among adults. The difference in the prevalences of coins as foreign bodies between ages groups was statistically significant $(p=0.001)$.

Discussion. Foreign bodies in the ears, nose or throat are commonly observed in otorhinolaryngology emergency services. ${ }^{9}$ They vary widely in shape, size, and composition. The symptoms may range from

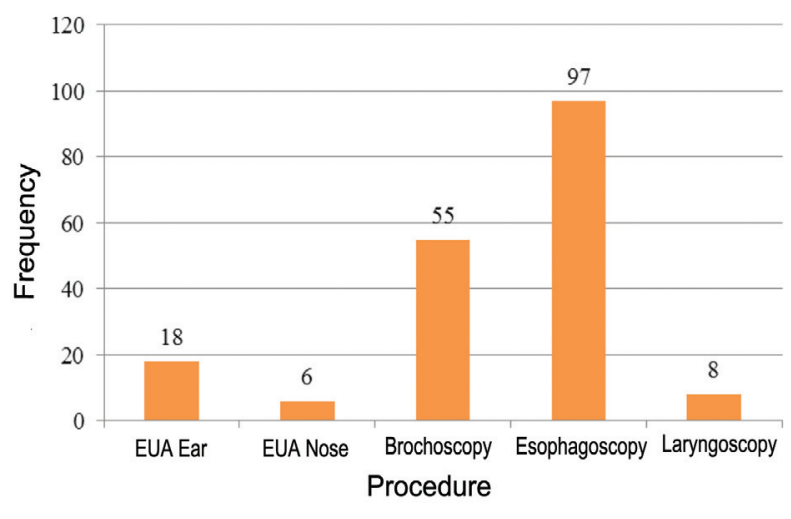

Figure 3 - Distribution of the study sample by procedure.

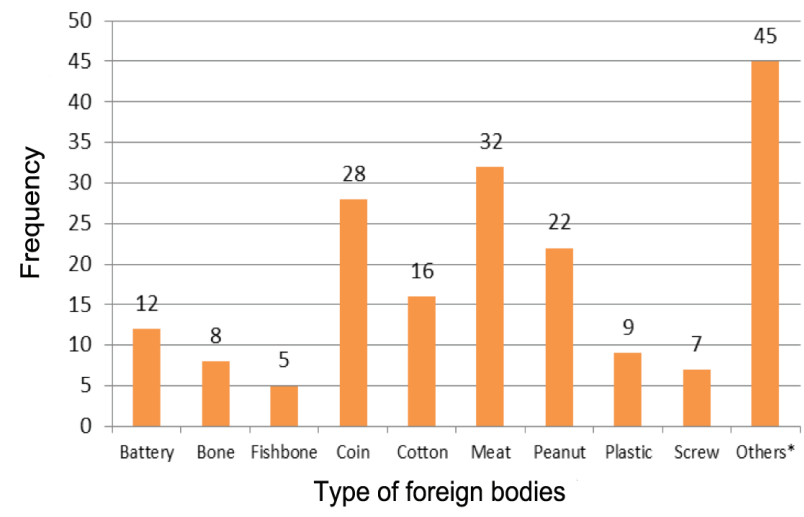

Figure 4 - Distribution of the study sample by type of foreign body.

asymptomatic to acute life-threatening symptoms. ${ }^{10} \mathrm{In}$ our study, the most common age group affected was preschool-aged children; the bronchus was found to be the most common site of foreign bodies in children, while the esophagus was the most common site in adults. In children, it could be due to the late arrival of patients to our tertiary hospital which may take 6-12 hours from insertion of foreign body to the hospital visit, this also could affect the site of foreign bodies in children. Impacted meat was the most common foreign body seen in adults specifically in handicap patients or those with esophageal abnormality associated with anatomic or motor abnormality like strictures, web achalasia, esophageal spasm and diverticula, this is consistent with other study, ${ }^{11}$ while coins were the most common foreign body in preschool-aged children. Children are mostly affected due to their tendency to put things in their mouth, their inability to masticate well, their inadequate control of deglutition, as well as 
their tendency to cry, shout and play during eating. ${ }^{12,13}$ In some studies, fish bone was the most common type discovered in oropharynx and hypopharynx, especially in both tonsils and piriform fossa. ${ }^{14}$ However, in our study, it was found that the most common type of foreign bodies were in the esophagus in adults and coins in the bronchus in children. This could be due to several factors, including the geographic location, nutritional habits of the patient and if the service is provided in a secondary or tertiary hospital. Most of fish bone foreign bodies were removed in secondary hospitals before the patient was referred to a tertiary care hospital. In general, ear foreign bodies are the most common foreign body encountered in children followed by nose and pharynx. ${ }^{15}$ This different from our study because our hospital is tertiary hospital which received difficult cases of foreign bodies of esophagus and trachea from secondary hospital of Aseer region. In elderly patients, edentate and poor masticating habits are predisposing factors. ${ }^{16-}$ ${ }^{18}$ Foreign bodies are usually ingested accidentally, but they may occasionally be ingested with homicidal or suicidal intent. Most nasal and aural foreign bodies can be easily removed in the emergency room or out patient department, but in some cases, the operating room may be required for simple foreign body dislodgement, especially in children. ${ }^{19-21}$ On the other hand, foreign bodies in the bronchus or esophagus must be treated in the operating room. In our study, the most frequent procedure was rigid esophagoscopy $(\mathrm{n}=97,53 \%)$, followed by rigid bronchoscopy $(n=55,30 \%)$. The management plan of foreign bodies' removal of upper airway depends on many factors like availability of wide range of instruments, endoscopic baskets, to achieve better outcome, ${ }^{22}$ general condition of the patients, severity of symptoms, size and type of foreign bodies and experience of surgeons. In our study, all procedures were carried out under general anesthesia using rigid endoscopy. Some foreign bodies are frustrating and challenging especially large items and those with sharp edges are most likely to become impacted in the larynx. In the other hand, inhaled foreign bodies that are round and non-compressible with smooth, slippery surfaces pose most risk of complete airway obstruction and death. Another important issue of controversy in management of foreign bodies in trachea is the type of anesthesia, there is a wide consensus on using sevoflurane or halothane as inhalational agents for induction of anesthesia and spontaneous breathing as a maintenance technique of choice. Urgent bronchoscopy is recommended for diagnostic or therapeutic purposes. These procedures may lead to serious complications, including upper airway obstruction, bradycardia, bronchospasm, laryngeal edema, pneumothorax, bleeding, esophageal perforation, mediastinitis, tooth breakdown, great vessel injury and increased risk of fatality. ${ }^{23-26}$ In our study, 4 patients out of 184 had complications with an incidence of $2 \%$, one child developed laryngeal spasm and emergency tracheostomy was carried out, foreign body was removed from trachea and he made uneventful recovery and discharge home after one week, other 3 patients developed laryngeal edema and hoarsens responded well to dexamethasone and racemic epinephrine.

Study limitations. Pediatric cases were transferred to a new hospital in Abha called Abha Children Hospital.

In conclusion, one of the success factor of management is making plan with an anesthetist to secure air way and to remove foreign body without complications like laryngeal spasm that may need emergency tracheostomy.

Acknowledgment. The authors would like to thank American Journal Experts (www.aje.com) for English language editing and author services for research publication.

\section{References}

1. Mangussi JG, Andrade JS, Matos RC, Kosugi EM, Penido ND. ENT foreign bodies: profile of the cases seen at a tertiary hospital emergency care unit. Braz J Otorhinolaryngol 2013; 79: 699-703.

2. Ray R, Dutta M, Mukherjee M, Gayen GC. Foreign body in ear, nose and throat: Experience in a tertiary hospital. Indian J Otolaryngol Head Neck Surg 2014; 66: 13-16.

3. Parajuli R. Foreign bodies in the ear, nose and throat: An experience in a tertiary care hospital in Central Nepal. Int Arch Otorhinolaryngol 2015; 19: 121-123.

4. Adedeji TO, Sogebi OA, Bande S. Clinical spectrum of ear, nose and throat foreign bodies in North Western Nigeria. Afr Health Sci 2016; 16: 292-297.

5. Svider PF, Vong A, Sheyn A, Bojrab 2nd DI, Hong RS, Eloy JA, et al. What are we putting in our ears? A consumer product analysis of aural foreign bodies. The Laryngoscope 2015; 125 : 709-714.

6. Davies PH, Benger JR. Foreign bodies in the nose and ear: a review of techniques for removal in the emergency department. J Accid Emerg Med 2000; 17: 91-94.

7. Yaroko AA, Irfan M. An annual audit of the ear foreign bodies in Hospital Universiti Sains Malaysia. Malaysian Family Physician 2012; 7: 2-5.

8. Olajide TG, Ologe FE, Arigbede OO. Management of foreign bodies in the ear: a retrospective review of 123 cases in Nigeria. Ear Nose Throat J 2011; 90: 16-19.

9. Onyeagwara N, Okhahku A, Emokpaire E, Ogisi F. Dynamics in the trend of foreign bodies in ENT practice in Nigeria: Any change. The Internet Journal of Otorhinolaryngology 2012; 14: (2). 
10. Mishra P, Bhakta P, Kumar S, Al Abri R, Burad J. Sudden near-fatal tracheal aspiration of an undiagnosed nasal foreign body in a small child. Emerg Med Australas 2011; 23: 776-778.

11. Lee CH, Chen TH, Ko JU, Yeh TH, Hsu WC, Kang KT. Ear, nose, and throat foreign bodies in adults: A population-based study in Taiwan. Journal of the Formosan Medical Association 2019; 118: 1291-1298.

12. Yeh B, Roberson JR. Nasal magnetic foreign body: a sticky topic. J Emerg Med 2012; 43: 319-321.

13. Ahmed K, Taous A. Case report unusual foreign body nose. Bangladesh J Otorhinolaryngol 2014; 20: 102-105.

14. Swain SK, Pani SK, Sahu MC. Management of fish bone impaction in throat. Our experiences in a tertiary care hospital of eastern India. Egyptian Journal of Ear, Nose, Throat and Allied Sciences 2017; 18.1: 27-30.

15. Amutta SB, Iseh KR, Aliyu D, Abdullahi M, Abdulrahaman GA. Ear, nose, and throat foreign bodies in a tertiary health institution in Sokoto, Nigeria. Sahel Medical Journal 2013; 16: 87.

16. Jariwalaa N, Kratimenosb P, Enga D, Gaughanc J, Koutroulisa I. Foreign body injuries in children: Are the younger siblings doomed? International Journal of Pediatrics and Adolescent Medicine 2016; 3: 7-11.

17. Mangussi JG, Andrade JS, Matos RC, Kosugi EM, Penido ND. ENT foreign bodies: profile of the cases seen at a tertiary hospital emergency care unit. Braz J Otorhinolaryngol 2013; 79: 699-703.
18. Endican S, Garap JP, Dubey SP. Ear, nose and throat foreign bodies in Melanesian children: an analysis of 1037 cases. Int J Pediatr Otorhinolaryngol 2006; 70: 1539-1545.

19. Chai CK, Tang IP, Tan TY, Jong DE. A review of ear, nose and throat foreign bodies in Sarawak General Hospital. A five year experience. Med J Malaysia 2012; 67: 17.

20. Bamber AR, Pryce J, Ashworth M, Sebire NJ. Fatal aspiration of foreign bodies in infants and children. Fetal Pediatr Pathol 2014; 33: 42-48.

21. Bir Singh G, Sidhu TS, Sharma A, Dhawan R, Jha SK, Singh N. Management of aural foreign body: An evaluative study in 738 consecutive cases. Am J Otolaryngol 2007; 28: 87-90.

22. Sepehr A, Albers GC, Armstrong WB. Aspiration of a capsule endoscope and description of a unique retrieval technique. Otolaryngol Head Neck Surg 2007: 137: 965-966.

23. Salih AM, Alfaki M, Alam-Elhuda DM. Airway foreign bodies: A critical review for a common pediatric emergency. World Journal of Emergency Medicine 2016; 7: 5.

24. Mukherjee A, Haldar D, Dutta S, Dutta M, Saha J, Sinha R. Ear, nose and throat foreign bodies in children: a search for socio-demographic correlates. Int J Pediatr Otorhinolaryngol 2011; 75: 510-512.

25. Jyothi AC, Shrikrishna BH, Sanjay G, Sandeep SG, Chaitanya V. A clinical study regarding foreign bodies in aerodigestive tracts. Odisha J Otolaryngol Head Neck Surg 2011; 5: 9-15.

26. Houston R, Powell S, Jaffray B, Ball S. Clinical guideline for retained button batteries. Arch Dis Child 2020; archdischild-2019-318354. 